\title{
Fire Vehicle Positioning Technology Based on Beidou System
}

\section{Zeng Li}

\author{
Department of fire Command, The Armed Police Academy, China
}

lizengluck@sohu.com

Keywords: Fire, Vehicle, Positioning, Beidou.

\begin{abstract}
Beidou satellite navigation system is used as the primary means of fire brigade vehicle management technology, which receives incoming data, coordinate conversion, map matching, display the appropriate vehicle location, speed and direction of travel of the vehicle and other information on the monitor, and then positioning system for fire vehicles evolution to plan for upgrade and maintenance of the system in the future to provide guidance.
\end{abstract}

\section{Introduction}

Fire VPS is used to transmit dynamic target position, including longitude, latitude, altitude, time and status information, to the control center via a wireless communication link. The system currently uses a GPS / GSM combination to achieve positioning communication functions. In order to solve the problem of drawbacks of positioning system currently used and avoid the risks of interruption.

Beidou satellite navigation system is used as the primary means of fire brigade vehicle management technology.

\section{Navigation Satellite System Of Beidou}

Beidou navigation system is China's homegrown, independent operation of global satellite navigation systems, which offers a global scale for all types of users with high precision, high reliable positioning data, navigation and timing services, and both short message communication capabilities all-weather, all-time. 16 navigation satellites has been successfully launched now, achieve the coverage of the Asia-Pacific region according to the plan, it is expected global coverage around 2020.

Beidou navigation system is composed of three parts of the special terminal, the ground terminal and the client parts, as shown in figure 1. Space side includes five satellites in geostationary orbit and 30 satellites on non-geostationary orbit. Ground terminal includes a main station, injection stations and other monitor stations and several ground stations. User terminal is compatible of the GPS, GLONASS, Galileo satellite navigation systems.

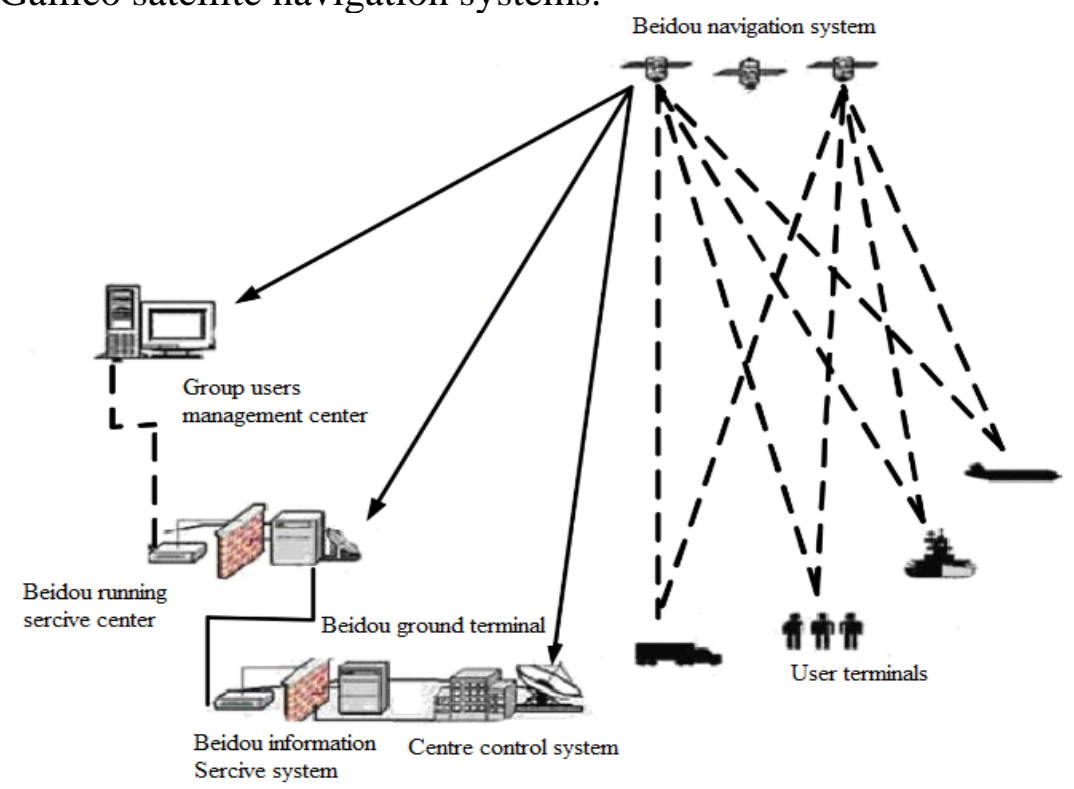

Fig. 1 The structure of the Beidou No.1 


\section{Fire Fighting Vehicles Beidou Navigation System}

Fire fighting vehicle positioning system is mainly composed of the following three parts: the vehicle terminal, the Beidou navigation system and command center. In the process of positioning, vehicle terminal receiving location information through the Beidou navigation system, then calculate the information of their actual location, speed, direction angle etc. through the communication function of Beidou satellite to the command center. Command center will display the real-time vehicle information through geographic information system module, and dispatch the target vehicle through the scheduling rules, the overall system block diagram is shown in figure 2.

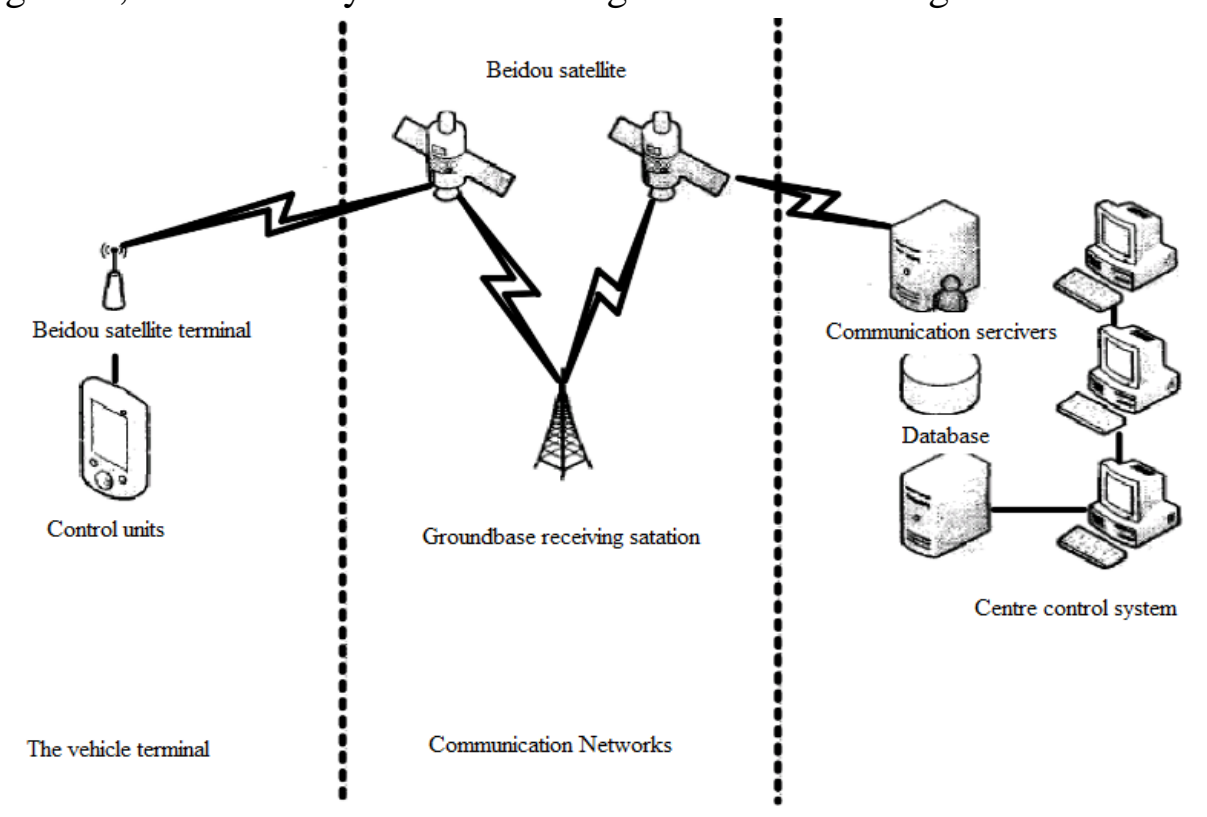

Fig. 2 The overall block diagram of the system hardware

In the fire vehicle monitoring system, according to the direction of data flow, the information in the system is divided into two categories. One is the upstream information, including location, the service application information, status information and alarm information. Another is descending information, including control information, scheduling information etc. The hierarchical system is shown in figure 3.

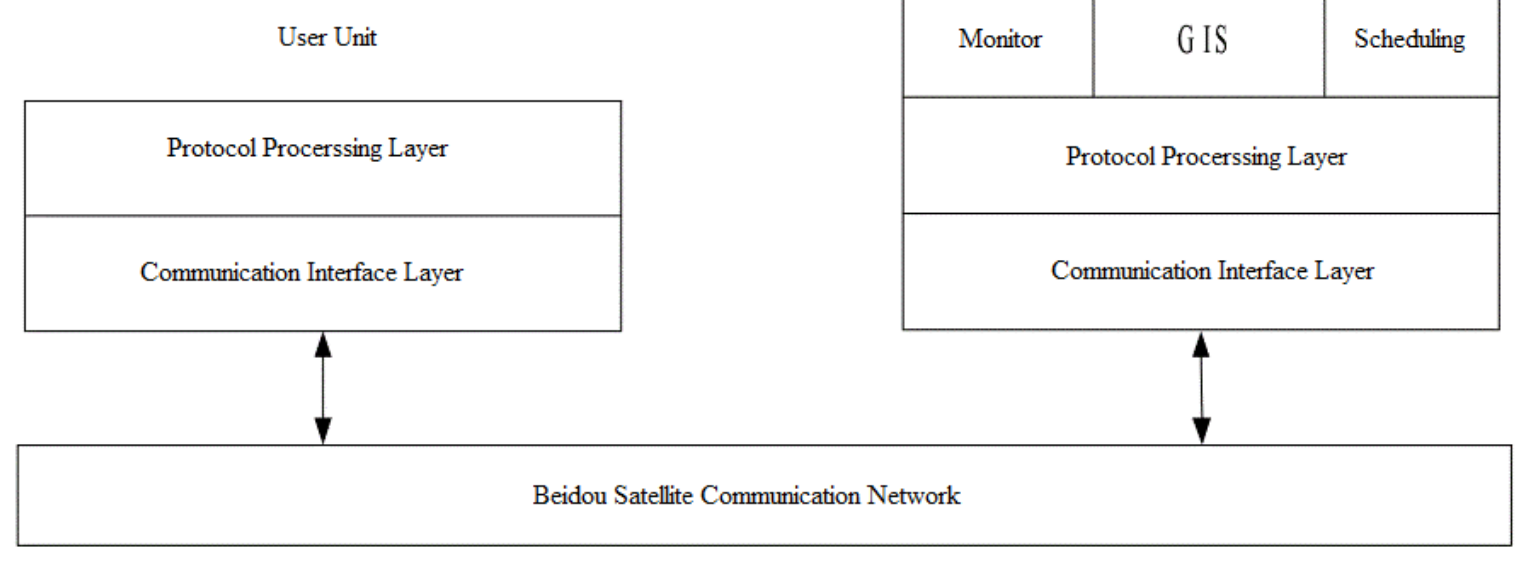

Fig. 3 The hierarchical of the Beidou satellite system

The structure of satellite positioning system based on the Beidou is $\mathrm{C} / \mathrm{S}$, mainly compose by command center, the device on vehicle and the communication network links them each other. The main service server which is also the command center includes: network communication service, vehicle dispatching service, GIS service, database service. The client refers to the communication 
subsystem, positioning subsystem and the GIS subsystem. The command center is the core of the whole system. It first receives a signal from a vehicle mounted unit, then analyzing the positioning information of the on-board unit according to a predetermined format, including the speed and direction information, then the data is stored in the database, and at last calling the corresponding service displaying real-time status, finally, complete the scheduling function.

\section{The Design Of Vehicle Terminal}

Vehicle positioning terminal is an important part of firefighting vehicle positioning system. All vehicle information including the specific running direction, the vehicle speed and the position information and so on obtained through vehicle terminal, Vehicle terminal can process the received information if it is necessary. This paper presents the realization of a vehicle terminal, including Beidou positioning module, Amplifier, frequency down-convert module, AD sampling, the baseband processing, navigation calculations, the data storage, ARM processor, USB peripherals, the display device, the data interface. Vehicle system diagram is shown in figure 4.

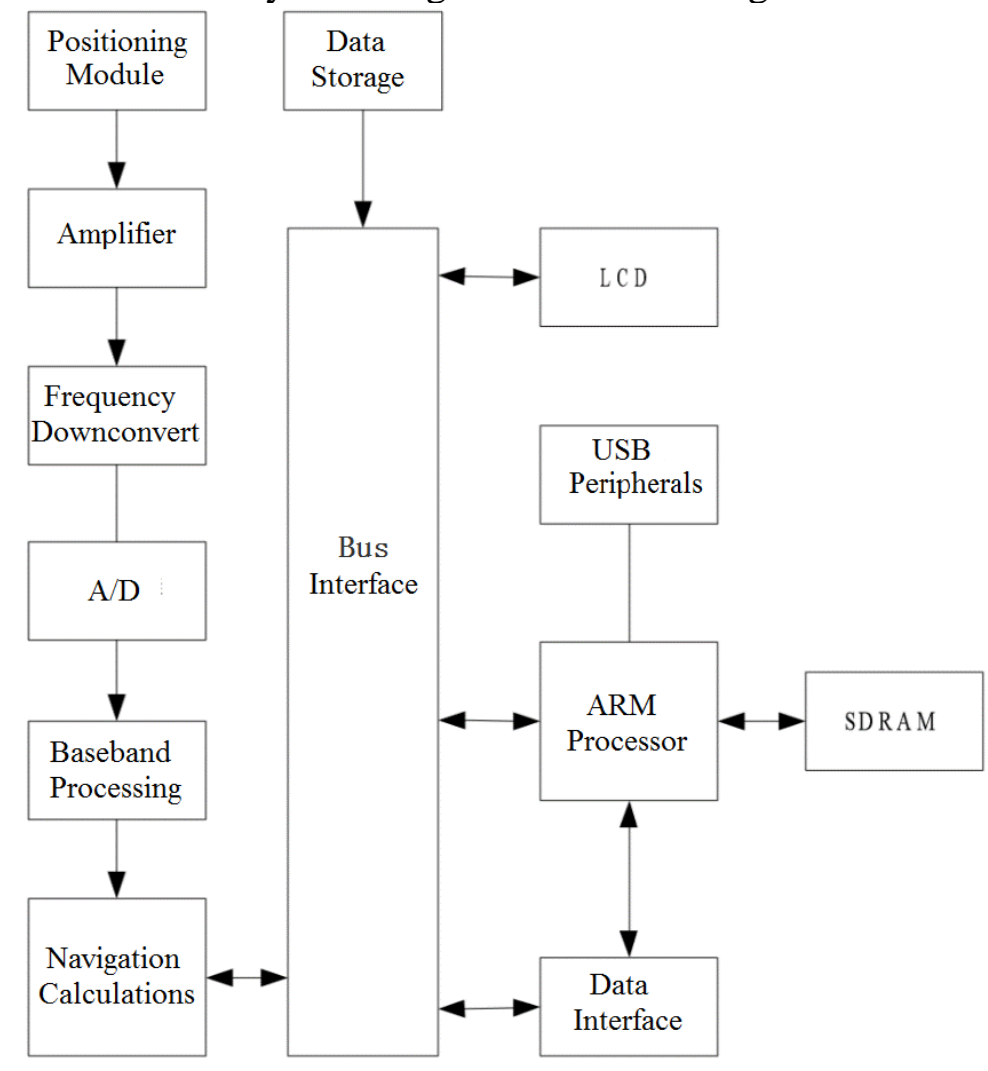

Fig. 4 The hardware of vehicle system diagram

The main function of the vehicle-mounted terminal software is that process the positioning information data receives from the serial port of Beidou Navigation System main control module, and and send the data in graphical form on a display vehicle terminal. Then it returns the processed information to the ground control center by the specific function of short message communication of Beidou navigation system. Therefore, vehicle-mounted software program includes a variety of modules initialization software, serial communication program, the Beidou satellite control procedures, data processing and control procedures. Among them, the main control module implements the initialization of ARM main control unit and Beidou navigation system whole.

When the main control module completes the initial of various components of the system, the positioning module and data sending module can be control via UART port. When the system determines that the received information is invalid, the Beidou satellite signal receiver module can be used again until the received signal is valid. If the data is valid, relevant various registers interrupted can be configured as external interrupts. When the key main control module is low, the external interrupt will take effect, the system judge that the user wants to send location information out, then 
Beidou satellite transmitter module is used, the data will be forwarded to the Beidou system, and then the data is forwarded to the ground control center.

\section{Command Center Receiving End Design}

Command Center is the core of the system, once the monitoring system fails, the whole system will collapse. The receiver is responsible for receiving command center positioning data from the user, as well as related issued control command. The receiving end of the command center is composed by a group of computers, has a strong computing power. The user systems are portable devices. Positioning information is transmitted between the user machine and the command center for two-way. In the command center, a dedicated database is built to support the operation of all information. All information will be stored in the central location database for appropriate treatment and subsequent operations. Performing scheduling, the system is also implemented to obtain the vehicle history data. Moreover, the command center will be able to form a GIS map data to display on the screen for easy real-time monitoring and decision-makers dispatching. Command center hardware block diagram is shown in figure 6.

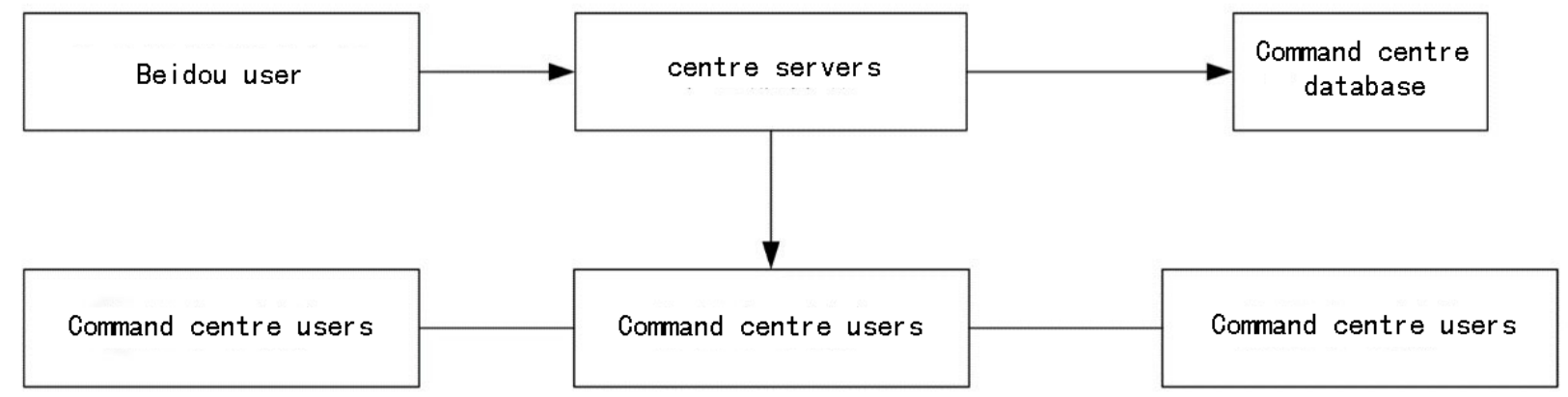

Fig.6 Command center hardware block diagram

\section{Summary}

Beidou Navigation System remains as an adjunct to complete positioning tasks in GPS positioning accuracy is low or the signal is not strong. Location information of vehicles priority transmitted to the command center through GSM / 3G / 4G / communications link when cellular signal data channel is less, using the Beidou system short message function to transmit information to the command center. Each command center began construct Command and Control System which can handle real-time traffic information and route out of the police vehicle for the optimal choice of, the road map can be display on a trip tickets for fire vehicles.

\section{References}

[1] Smith, Gordon James, and George Willard Van Leeuwen. Emergency vehicle locator and proximity warning system [D] . U.S. Patent No. 6,529,831. 4 Mar. 2003.

[2] Pillar, Duane, and Bradley Squires.Firefighting vehicle with network-assisted scene management[D].2002.

[3] Hall, Timothy J., Steven M. Hamer, and Mark A. Schwartz. GPS-based traffic control preemption system[D]. U.S. Patent No. 5,539,398. 23 Jul. 1996.

[4] Lemelson, Jerome H., and Robert D. Pedersen. GPS vehicle collision avoidance warning and control system and method [D]. U.S. Patent No. 5,983,161. 9 Nov. 1999.

[5] HE, Xiao-wei, Ai-hua WANG, and Yue MA.Research of GPS vehicle terminal communication technology based on GPRS [J].Journal of Computer Applications, 2008,11: 62-66. 